\title{
Lesions of the Dorsal Hippocampal Formation Interfere with Background but Not Foreground Contextual Fear Conditioning
}

Russell G. Phillips and Joseph E. LeDoux ${ }^{1,2}$

Department of Psychology and ${ }^{1}$ Center for Neural Science

New York University

New York, New York 10003

\begin{abstract}
The effects of hippocampal lesions on the conditioning of fear responses (freezing responses) to contextual stimuli (static, continuously present stimuli) were examined in three conditioning paradigms: forward pairing of a phasic tone conditioned stimulus (CS) with a footshock unconditioned stimulus (US), unpaired presentations of the CS and US, or presentations of the US alone. All three procedures resulted in the acquisition of conditioned freezing to contextual stimuli. Lesions of the dorsal hippocampus prevented the acquisition of contextual conditioning in the Paired procedure, as reported previously, but not in the Unpaired or US Alone procedures. In the Paired procedure, static contextual cues occur in the background, with the phasic tone CS being the primary stimulus that enters into the association with the US. However, in the other two procedures, where there is no phasic CS, the primary associations with the US involve static contextual stimuli, which are therefore in the foreground. We refer to these types of contextual conditioning as background and foreground contextual conditioning, respectively, and argue that the hippocampus is only involved in background contextual conditioning. These results have implications for understanding both fear conditioning and hippocampal function.
\end{abstract}

\footnotetext{
${ }^{2}$ Corresponding author.
}

\section{Introduction}

Classical fear conditioning is an experimental procedure in which an aversive unconditioned stimulus (US), such as footshock, is presented in association with a neutral conditioned stimulus (CS), often an auditory tone or flashing light (e.g., Estes and Skinner 1941; Brown et al. 1951; Hunt and Brady 1955; Kamin et al. 1963, McAllister and McAllister 1971; Bolles and Fanselow 1980; Bouton and Bolles 1980). After repeated pairings, the CS begins to elicit conditioned emotional (fear) responses (measured by suppression of instrumental responses, freezing behavior, changes in autonomic activity, and facilitation of reflex action) when presented alone. Fear conditioning is a rapidly acquired and long-lasting form of learning and is therefore an attractive model for studying the neural basis of learning and memory, specifically, emotional learning and memory (Davis 1992; Kapp et al. 1992; LeDoux 1992).

Stimuli present in the environment where a US is presented but not explicitly paired with the US in a temporally specific manner may also acquire aversive properties and thereby elicit conditioned emotional responses (Blanchard and Blanchard 1972; Rescorla and Wagner 1972; OdlingSmee 1975; Bouton and Bolles 1980; Fanselow 1980, 1990; Bolles and Fanselow 1980; Marlin 1982; Bouton and King 1983). Such responses are said to be conditioned to static, background, or contextual cues.

Most studies of the neural basis of fear conditioning have focused on the conditioning that occurs to an explicit, phasic CS (e.g., LeDoux 1990, 1992; Davis 1992; Kapp et al. 1992). However, recent studies have begun to examine the neural basis of contextual fear conditioning as well (Kim

LEARNING \& MEMORY 1:34-44 (c) 1994 by Cold Spring Harbor Laboratory Press ISSN1072-0502/94 \$5.00

$$
\begin{array}{llllllllllllllll}
L & E & A & R & N & I & N & G & \begin{array}{l}
\boldsymbol{Q} \\
34
\end{array} & M & E & M & O & R & Y
\end{array}
$$


and Fanselow 1992; Phillips and LeDoux 1992). Findings to date suggest both overlap and divergence of the pathways underlying the conditioning of fear reactions to a CS and to context. The amygdala is involved in both CS and contextual fear conditioning, but the hippocampal formation is only involved in contextual fear conditioning.

The term context is sometimes used to refer to static background stimuli, or stimuli other than the phasic CS that are continuously present in the immediate environment where the US occurs. Because they are unchanging, the static stimuli tend to be less salient than the phasic CS and less predictive of the US than the phasic CS. Conditioning to static stimuli thus tends to be overshadowed by the phasic CS (Kamin 1968, 1969; Odling-Smee 1978; Rickert et al. 1979). Although the associations formed between the overshadowed background stimuli and the US are usually weaker than the association between the phasic CS and the US, the background stimuli nevertheless compete with the phasic CS for associative strength (Rescorla and Wagner 1972; Gibbon and Balsam 1981; Marlin 1981; Balaz et al. 1982; Miller and Matzel 1988). However, the term context can also refer to static (continuously present) stimuli that serve as the primary events that are associated with the US. This occurs when there is no phasic CS that is explicitly paired with the US. Such stimuli, though static, are in the conditioning foreground. With respect to context, fear conditioning procedures where there is and is not a phasic CS that is explicitly paired with a US can be referred to as background and foreground contextual fear conditioning, respectively.

Foreground and background contextual conditioning lead to similar outcomes: Subjects exhibit conditioned fear responses, such as freezing (Blanchard and Blanchard 1969a; Bouton and Bolles 1980; Fanselow 1980), when later placed in the conditioning apparatus. However, the procedures differ in important ways. In background contextual conditioning, the phasic CS predicts when the US will occur while the static cues are redundant. However, in foreground contextual conditioning, the subject only has static cues available. Although static cues do not predict when the US will occur, they do indicate that the subject is in a situation in which the US is likely to occur. Thus, freezing to context after foreground contextual conditioning is a conditioned response that is controlled by the primary (albeit static) stimulus event or events associated with and predictive of the US during conditioning, whereas freezing to context after background conditioning is a conditioned responses that is not under the control of the primary stimulus event or events that were associated with and predictive of the US during conditioning. This distinction between background and foreground contextual stimuli is not usually made in the experimental or theoretical literature on conditioning. However, as a result of important differences between conditioning procedures involving background and foreground contextual stimuli, different information-processing functions probably mediated by different neural mechanisms may be required.

The purpose of this study was to determine whether damage to the hippocampal formation has different effects on contextual fear conditioning when the contextual stimuli are in the foreground or background. Three different training procedures were used. In the first procedure, a phasic CS (tone) was paired with the US; in the second procedure, the CS and US were explicitly unpaired; and in the third, the US was presented alone. The first procedure (CS-US pairing) is a background contextual conditioning procedure and is a replication of our previous study demonstrating that hippocampal lesions interfere with the acquisition contextual fear conditioning (Phillips and LeDoux 1992). In contrast, the latter two procedures (Unpaired CS-US and US Alone) are foreground contextual conditioning procedures. Our results suggest that hippocampal damage only interferes with acquisition of background contextual fear conditioning.

\section{Materials and Methods}

\section{ANIMALS}

Male Sprague-Dawley rats, which weighed 250-275 grams on arrival, were housed in groups of two for 1 week after arrival to become acclimatized to laboratory conditions. They were provided with free access to lab chow and water and were maintained on a 12:12 hr light-dark cycle.

\section{SURGERY}

About 7 days after arrival, animals were anesthetized with pentobarbital $(40 \mathrm{mg} / \mathrm{kg})$ and placed in a stereotaxic frame. The cranium was

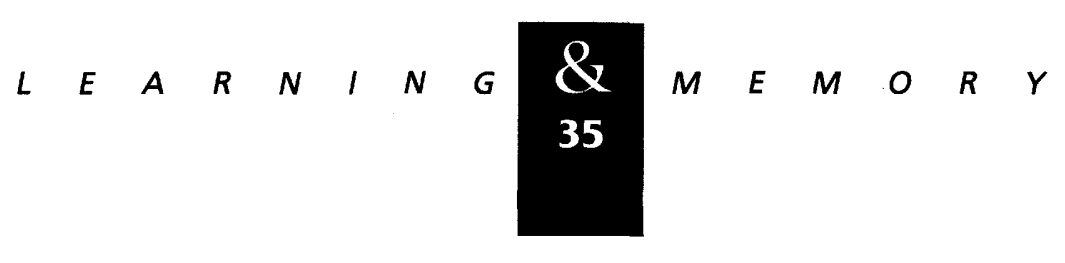


exposed, and a small burr hole was made over the lesion site using a dental drill. Monopolar stainless steel electrodes insulated with epoxy to within $200 \mu \mathrm{m}$ of the tip were lowered through an incision in the dura to the dorsal hippocampus. The cathode was connected to the open skin wound. Lesions were made by passing anodal constant current ( $1 \mathrm{~mA}, 15-20 \mathrm{sec})$ through the electrode. All lesions were bilateral, with placement guided by coordinates modified from an atlas of the rat brain (Paxinos and Watson 1986). The anterior-posterior (AP), medial-lateral (ML), and dorsal-ventral (DV) coordinates were computed in relation to the interaural line. Dorsal hippocampal lesions were made in three locations bilaterally: (1) $\mathrm{AP}=6.0, \mathrm{ML}= \pm 1.8, \mathrm{DV}=3.0$ from dura; (2) $\mathrm{AP}=5.0, \mathrm{ML}= \pm 3.0, \mathrm{DV}=3.0$ from dura; and (3) $\mathrm{AP}=4.0, \mathrm{ML}= \pm 3.0, \mathrm{DV}=3.0$ from dura. After surgery the wound was sutured and the animal was placed under a heat lamp until recovery from anesthesia was complete. Animals were then returned to the housing area and allowed to recover for 10-14 days before training began. Controls were either unoperated or underwent the same surgery as lesioned animals with the exception that no current was passed through the electrode. As performance was not different in operated and unoperated controls, they were combined to form the control groups.

\section{APPARATUS}

Rats were placed individually into a rodentconditioning chamber (Coulbourn Instruments, Lehigh Valley, PA, model E10-10) enclosed by a sound-attenuating cubicle (Coulbourn Instruments, model E10-20). Stimulus presentation was controlled by a microprocessor and a digital $\mathrm{I} / \mathrm{O}$ board (Opto 22). The CS (if required) was a 10$\mathrm{kHz}$ tone produced by a frequency generator (Coulbourn Instruments, model S81-06), amplified to $75 \mathrm{~dB}$, and presented for $20 \mathrm{sec}$ through a speaker located in the front panel of the chamber. The US was a brief $(500 \mathrm{~ms})$ distributed delivery of direct current $(0.5 \mathrm{~mA})$ produced by a grid floor shocker (Coulbourn Instruments, model E13-08).

\section{PROCEDURE}

Lesioned and control rats were assigned to one of three treatment groups: Paired CS-US, Un- paired CS-US, or US Alone. On day 0, the animals were placed in the conditioning apparatus for 20 min with no stimuli presented. On days 1 and 2, conditioning trials were given during which two US presentations occurred with an ITI of $60-120$ sec. For animals in the Paired groups, the 20-sec CS coterminated with the US. The Unpaired groups received two presentations of the US (on the same schedule as for the Paired Group) and two presentations of the CS (on a pseudorandom schedule with respect to the US, but not overlapping in time with the US). The US Alone groups received only the US presentations with the same schedule of US delivery as the other groups. On day 3, the Paired and Unpaired groups received the CS on the same schedule as on the previous 2 days but without the US.

Freezing was used as an index of conditioned fear (Blanchard and Blanchard 1969a,b; Bouton and Bolles 1980; Fanselow 1980; LeDoux et al. 1984,1990 ) and was assessed by viewing the animals through a peephole in the sound-attenuating chamber. Freezing involved the absence of all movement, except for respiratory-related movements, while the animal was in the stereotyped crouching posture (Blanchard and Blanchard 1969a). Freezing is readily distinguished from resting by the crouching posture and by the fact that rats never lie down when they are freezing. Contextual fear conditioning was assessed by measuring freezing during the $20 \mathrm{sec}$ prior to the onset of the first CS on each day for the Paired and Unpaired groups. Freezing to context was measured during the $20 \mathrm{sec}$ that preceded US onset by 40 sec (or when the US should occur, for day 3 ) in the US Alone group. Freezing was also measured during the first 20 -sec CS on each day for the Paired and Unpaired groups. Freezing was measured during the first trail of each day because this trial reflects the learning that occurred as a result of conditioning trials on the previous day, and, unlike measurements during the second trial of the day, measurements during the first trail are not confounded by prior CS or US presentation on the same day (Phillips and LeDoux 1992). The observer was not blind to the experimental treatment.

\section{HISTOLOGY}

After completion of behavioral studies, animals were given an overdose of sodium pentobar-

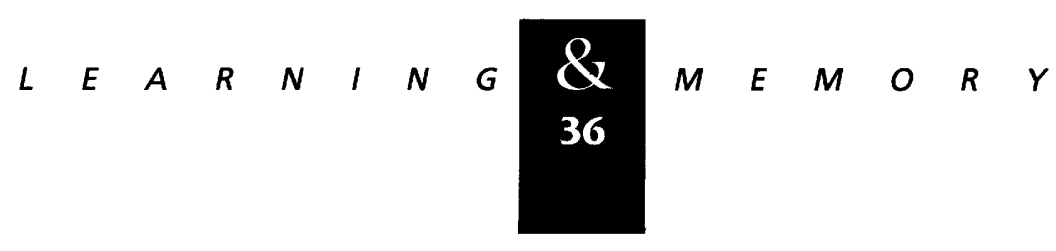


bital ( $120 \mathrm{mg} / \mathrm{kg}$ ) and transcardially perfused with physiological saline, followed by $10 \%$ buffered formalin. Brains were postfixed in buffered formalin for 1 day to 2 weeks, frozen, and cut on a sliding microtome into $40-\mu \mathrm{m}$ sections. Every fourth section was collected in phosphate buffer, mounted on a gelatin-coated slide, allowed to air-dry, and stained with thionine.

\section{Results}

Lesions of the dorsal hippocampus were made in 54 rats. Lesion location was plotted from Nisslstained, $40-\mu \mathrm{m}$ sections spaced $250 \mu \mathrm{m}$ apart. The lesions usually included the dentate gyrus, dorsal CA1, CA2, and CA3 fields, and the dorsal subiculum. Some lesions extended into the cortex above hippocampus and underlying thalamus. Animals were included in the data analysis if all areas of the dorsal hippocampus were destroyed completely (medial to lateral and dorsal to ventral) at one level along the rostrocaudal axis. Previously, we found that lesions meeting this criterion were more likely to be effective in disrupting contextual conditioning in animals given Paired training than lesions that failed to meet this criterion (unpublished observation based on findings reported in Phillips and LeDoux 1992). The lack of effect of hippocampal damage in rats given Unpaired training in pilot studies compelled us to use a strict criterion to maximize the likelihood of seeing an effect of hippocampal damage on foreground contextual conditioning. Following this criterion, 15 animals had acceptable hippocampal lesions (Paired group, $n=5$; Unpaired group, $n=5$; US
Alone group, $n=5$ ). The remaining lesioned animals were excluded from the analysis. A representative lesion is illustrated in Figure 1. This lesion was characteristic of the accepted lesions in all three training conditions. Controls were either unoperated or had electrodes inserted into the dorsal hippocampus without passing current. No differences were found between animals in these control procedures, which were mixed to construct the three control groups (Paired, $n=9$; Unpaired, $n=5$; US Alone, $n=9$ ).

The effects of dorsal hippocampal lesions on the acquisition of a conditioned fear response to continuously present contextual stimuli were examined by measuring the amount of time spent "freezing" during a designated context test period. For animals in the Paired and the Unpaired groups, the context test period was the 20 sec preceding the onset of the first CS presentation of each day. For animals in the US Alone groups, the context test period started $40 \mathrm{sec}$ prior to the occurrence of the first US of the day, the time that the test would have started if there had been a CS. Freezing was also measured during the presentation of the first CS of each day for animals in the two training conditions in which a CS was presented (Paired and Unpaired training).

The acquisition of conditioned freezing responses to static environmental stimuli by unlesioned control rats and by rats with dorsal hippocampal lesions in the three different training procedures is shown in Figure 2 and Table 1. On day 1 , little or no freezing was recorded for any animal in any of the groups during the context test time, which preceded the delivery of the two US pre-

Figure 1: Coronal sections of the rat brain illustrating a typical lesion of the dorsal hippocampal region. The lesioned area is shown by stippling. Lesions typically included damage to all CA fields, the dentate gyrus, and the dorsal subiculum. The templates of the coronal sections were taken from Paxinos and Watson (1986). Level $A$ is the most caudal section, and level $F$ the most rostral.
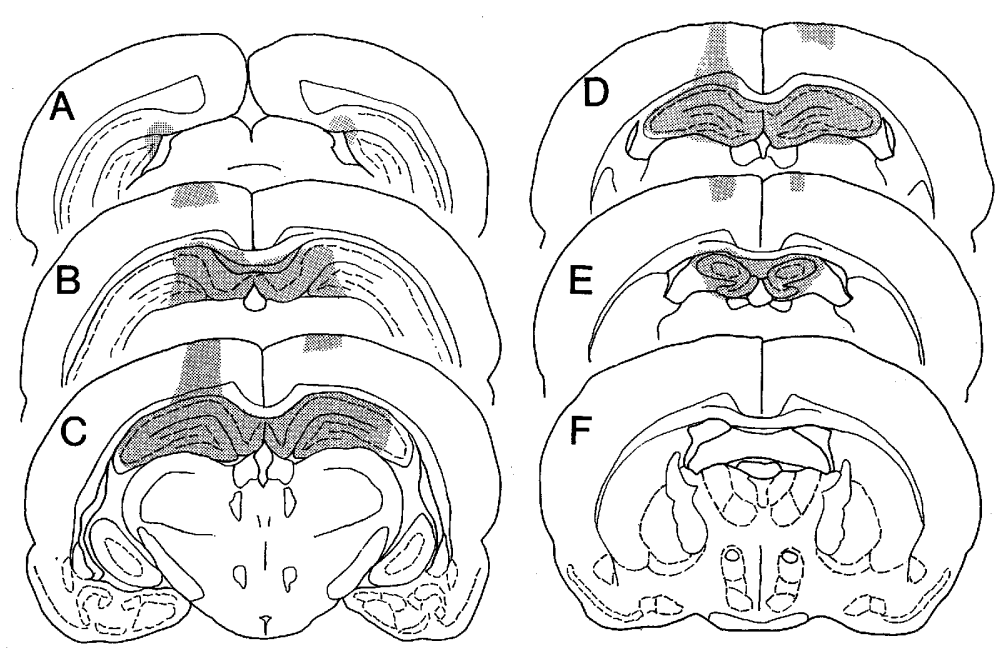

$$
\begin{array}{lllllllll}
L & E & A & R & N & I & N & G & \& \\
37 & M & E & M & O & R & Y
\end{array}
$$




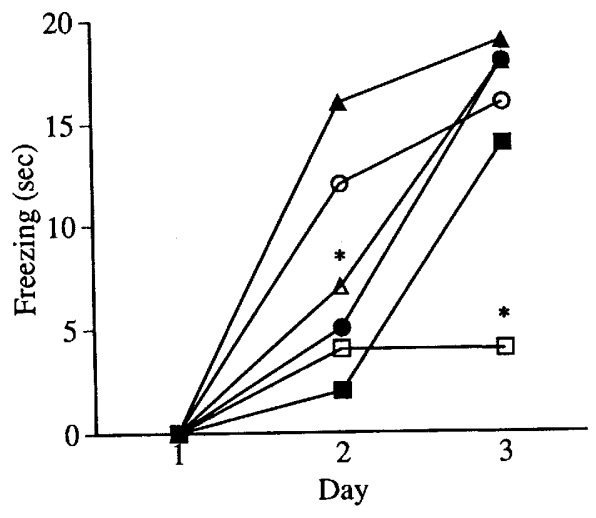

Figure 2: Amount of freezing elicited by static contextual stimuli across days for control (Ctrl) and dorsal hippocampal lesioned (Hip) animals in the Paired, Unpaired, and US Alone groups. By day 3 , the only group that failed to condition to contextual stimuli was the hippocampal lesioned group given Paired training. Thus, on day 3 , the amount of freezing to contextual stimuli in the hippocampal group given Paired training was significantly different from the amount of freezing in the Paired control group, but the hippocampal lesioned animals given Unpaired and US Alone training did not differ from their control groups. The Unpaired lesioned group conditioned to context more slowly than the Unpaired control group (as indicated by the significant difference on day 2), but the Unpaired lesioned group conditioned to context at the same rate as the other two control groups (see Discussion). For clarity, error bars are omitted, but error terms are presented in Table 1. Statistical differences between control and lesion groups within each training procedure on a given day are shown $\left({ }^{*}=P<0.01\right)$. ( $\square$ ) Paired control; ( $\square$ ) Paired hip; (ム) Unpaired control; $(\triangle)$ Unpaired hip; (O) US Alone control; (O) US Alone hip. For details of statistical analysis, see Results.

sentations (and CS presentations in the Paired and Unpaired groups). Animals in all three groups exhibited exploratory-like movement throughout the context test time on day 1 . On day 2 , after two US presentations on the previous day, control animals in the Paired and the US Alone groups still showed little freezing to the context, averaging $\leqslant 5 \mathrm{sec}$ of freezing out of $20 \mathrm{sec}$. In contrast, control animals in the Unpaired group exhibited freezing for $17 \mathrm{sec}$ on average during the 20 -sec context test period on day 2 . By day 3 , controls in all three training conditions exhibited relatively high levels of freezing ( $\geqslant 14 \mathrm{sec}$ out of 20 , on average) during the context test time. Hippocampal lesioned rats in the Paired and Unpaired procedures exhibited little freezing on day 2 (averaging 4 and
$7 \mathrm{sec}$, respectively), with somewhat higher levels ( 12 sec on average) present in the US Alone group. By day 3, the lesioned animals given Unpaired and US Alone training exhibited high levels of freezing (averaging 18 and $16 \mathrm{sec}$ ), but hippocampal lesioned rats in the Paired group still exhibited little freezing ( $5 \mathrm{sec}$, on average) during the context test time.

The effect of hippocampal lesions on the conditioning of freezing responses to contextual cues was analyzed across days for each training procedure (Paired, Unpaired, and US Alone) by performing an analysis of variance with two grouping variables (Training Procedure and Surgery) and one repeated measure (Day). There was a main effect of Day $[\mathrm{F}(2,64)=109.22, P<0.001]$ and Training Procedure $[\mathrm{F}(2,32)=10.09, P<0.001]$ but not of Surgery $[F(1,32)=1.91), P>0.05]$. In addition, there was a significant two-way interaction between Day and Training Procedure $[\mathrm{F}(4,64)=4.12, P<0.01]$ but not between Day and Surgery $[\mathrm{F}(2,64)=1.8, P>0.05]$ or Training Procedure and Surgery $[\mathrm{F}(2,32)=2.17, P>0.05]$. Furthermore, a significant three-way interaction was found between the three factors $[F(4,64)=5.247$, $P<0.001$ ], suggesting that hippocampal damage affected performance under some training conditions on some days.

Post hoc individual $t$-tests (using the Bonferoni correction) were performed to identify the locus of significant effects. We were initially interested in the difference between control and lesion groups within each training procedure on day 3 (the time point at which controls in all three groups showed substantial freezing responses during the context test). A significant difference was found between the control and hippocampal lesioned animals in the Paired procedure $[t(64)=2.5, P<0.01]$, but not in other procedures, on day 3. Thus, hippocampal damage prevented the acquisition of contextual conditioning in the Paired but not the Unpaired or US Alone procedures. A significant effect was also found on day 2 between control and lesioned groups given Unpaired training $[t(64)=2.77, P<0.01]$. Thus, hippocampal damage only interferes with the acquisition of contextual conditioning in the Paired group (as shown by the day 3 results). Although hippocampal damage slows the rate of acquisition in Unpaired procedure (as shown by the day 2 results), these animals condition to context by the next day. Furthermore, this slowing of acquisition is only relative to the Unpaired control group.

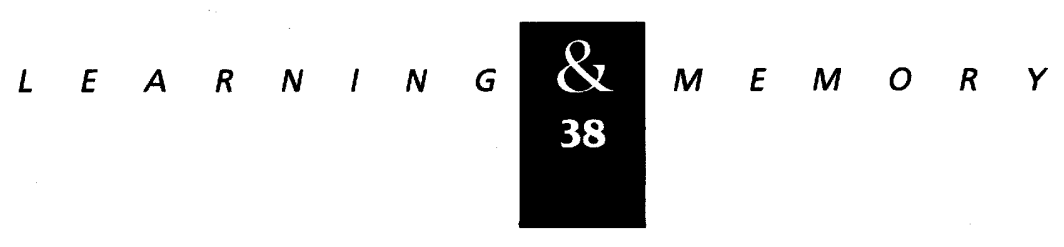


Table 1: Conditional freezing responses to static environmental stimuli of control and dorsal hippocampal lesioned rats in the three training groups

\begin{tabular}{|c|c|c|c|c|c|c|c|}
\hline & \multirow[b]{2}{*}{ Day } & \multicolumn{2}{|c|}{ Paired } & \multicolumn{2}{|c|}{ Unpaired } & \multicolumn{2}{|c|}{ US Alone } \\
\hline & & $\begin{array}{l}\text { control } \\
(n=9)\end{array}$ & $\begin{array}{l}\text { lesion } \\
(n=5)\end{array}$ & $\begin{array}{l}\text { control } \\
(n=5)\end{array}$ & $\begin{array}{l}\text { lesion } \\
\quad(n=5)\end{array}$ & $\begin{array}{l}\text { control } \\
(n=9)\end{array}$ & $\begin{array}{l}\text { lesion } \\
\quad(n=5)\end{array}$ \\
\hline \multirow[t]{3}{*}{ Context } & 1 & 0 & 0 & 0 & 0 & 0 & 0 \\
\hline & 2 & $2( \pm 2.2)$ & $4( \pm 1.8)$ & $17( \pm 2.5)$ & $7( \pm 3.4)$ & $5( \pm 1.8)$ & $12( \pm 3.7)$ \\
\hline & 3 & $14( \pm 1.8)$ & $5( \pm 3.7)$ & $19( \pm 0.6)$ & $18( \pm 1.0)$ & $18( \pm 0.8)$ & $16( \pm 4.0)$ \\
\hline \multirow[t]{3}{*}{$\mathrm{CS}$} & 1 & 0 & 0 & 0 & 0 & & \\
\hline & 2 & $12( \pm 2.0)$ & $9( \pm 2.7)$ & $10( \pm 3.5)$ & $1( \pm 1.0)$ & & \\
\hline & 3 & $14( \pm 1.5)$ & $16( \pm 1.0)$ & $12( \pm 3.2)$ & $11( \pm 4.0)$ & & \\
\hline
\end{tabular}

Data presented are averages within training and lesion groups ( \pm S.E.). For details of statistical analysis, see Results.

That is, the Unpaired lesioned group conditioned at the same rate as controls in the other training procedures (Paired and US Alone), which also condition slower than the Unpaired control group.

Conditioned freezing in the presence of the phasic CS was analyzed in the two training procedures in which an explicit CS was presented (Paired and Unpaired). The average freezing scores during the CS over the 3 days are shown in Figure 3 and Table 1 . An analysis of variance with two grouping factors (Training Procedure and Surgery) and one repeated measure (Day) was performed. There was a main effect of Day $[F(2,40)=50.7, P<0.001]$ and Training Procedure $[\mathrm{F}(1,20)=4.7, P<0.05]$ but not of Surgery $[\mathrm{F}(1,20)=2.0, P>0.05]$. The Day by Surgery interaction was significant $[\mathrm{F}(2,40)=4.0, P<0.05]$, but the Surgery by Training Procedure $[\mathrm{F}(1,20)=0.86, P>0.05]$ and the Day by Training Procedure $[F(2,40)=2.0, P>0.05]$ interactions were not. Also, the three-way interaction was not significant $[\mathrm{F}(2,40)=0.68, P>0.05]$. Post hoc $t$-tests (using the Bonferoni correction) comparing lesion and control groups within Training Procedures on days 2 and 3 showed that the main factor accounting for the Day by Surgery interaction was the difference on day 2 between the control group and lesioned group given Unpaired training $[t(40)=2.5, P<0.01]$. The amount of freezing during the CS on day 3 was thus not different between the Paired and Unpaired procedures, suggesting that these produced similar amounts of excitatory conditioning.

High levels of freezing to the CS in the Unpaired group complicate the interpretation of freezing to the CS in the Paired group (in the ab- sence of a difference between responses to the CS in the Paired and Unpaired procedures, it is not possible to distinguish between the contribution of associative and nonassociative factors to the conditioned response). However, because the CS test time immediately followed the context test time, it is possible that freezing during the CS might reflect conditioning to contextual stimuli rather than to the CS, especially in the Unpaired procedure where the CS is not specifically associ-

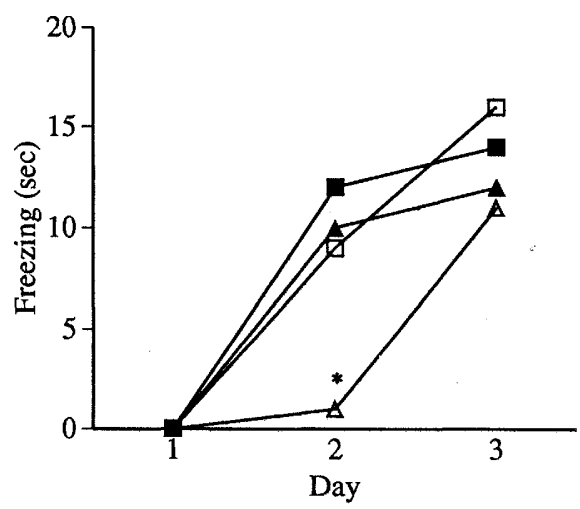

Figure 3: Amount of freezing elicited by the phasic CS across days for control (Ctrl) and dorsal hippocampal lesioned (Hip) animals in the Paired and Unpaired groups. With Paired training, animals in both control and lesioned groups exhibited relatively high levels of freezing to the CS on days 2 and 3 . Unpaired controls and lesioned animals also exhibited freezing to the CS (controls on day 2 and 3 , lesions on day 3). However, as shown by the data in Fig. 4 and as explained in Results, freezing to the CS in the Unpaired animals appears to reflect freezing to the context rather than to the CS. Error bars are omitted in this figure but are presented in Table $1\left(^{*}=P<0.01\right)$. (For symbols, see legend to Fig. 2.)

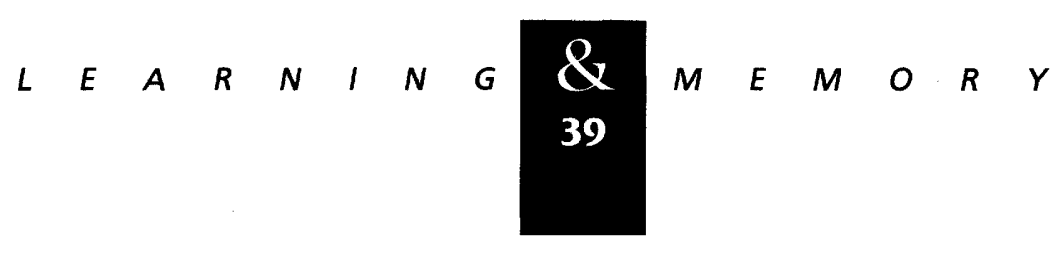


ated with the US. We therefore reanalyzed freezing during the CS test time relative to the context test time in the Paired and Unpaired groups, with results from days 2 and 3 combined for each animal and with data from lesion and control groups given the same training combined. As shown in Figure 4, animals given Paired training show relatively more freezing to the CS than to the context, and animals given Unpaired training show relatively more freezing to the context than to the CS. An analysis of variance performed on these data resulted in nonsignificant effects of stimulus type [CS vs. context: $F(1,22)=1.03, P>0.05]$ and training type [Paired vs. Unpaired: $F(1,22)=0.97$, $P>0.05$ ] but a significant interaction between stimulus type and training type $[\mathrm{F}(1,22)=22.97$, $P<0.001$ ]. Post hoc paired $t$-tests (with context and CS scores for each animal paired) were conducted. Freezing during the CS and context differed for animals in both the Paired $[t(13)=3.79$, $P<0.001]$ and the Unpaired $[t(9)=3.04, P<0.05]$ training procedures. Thus, freezing during the CS

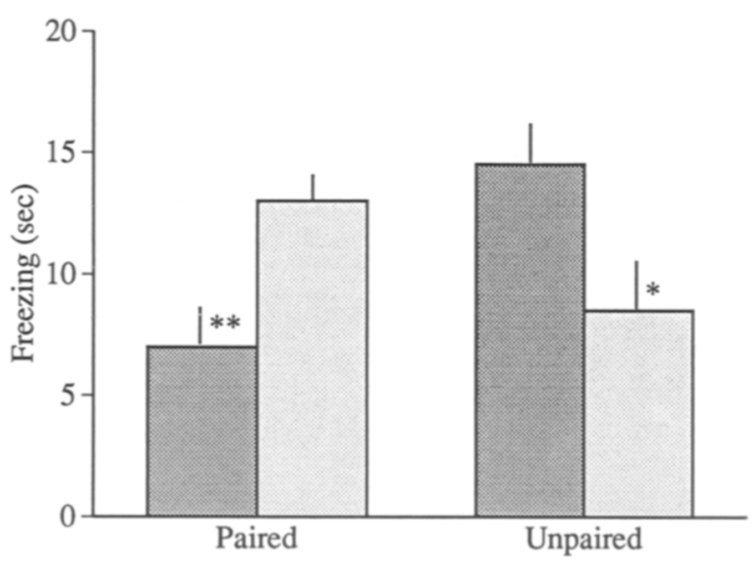

Figure 4: Amount of freezing elicited by static contextual stimuli and the phasic CS in the groups given Paired and Unpaired training (the two training procedures that involved a phasic CS). Data shown are averages across days 2 and 3 . Within each stimulus type (context and $\mathrm{CS})$ results are collapsed across lesion and control animals to illustrate the effects of stimulus type. Animals in the Paired groups tended to freeze more during the CS test time, whereas animals in the Unpaired groups tended to freeze more during the context test time, supporting the conclusion that freezing during the CS in the Paired groups reflects excitatory conditioning to the CS and freezing to the $\mathrm{CS}$ in the Unpaired groups reflects excitatory conditioning to the context (see Results for further explanation; ${ }^{*}=P<0.05 ;{ }^{* *}=P<0.01$ ). Dark shading indicates context; light shading indicates CS. appears to reflect excitatory conditioning to the CS in the Paired group but to the context in the Unpaired Group. In the Unpaired group, the subjects freeze less when the CS is present, suggesting that the explicitly unpaired CS acquires inhibitory properties, as others have suggested (Rescorla and Wagner 1972; Cunningham 1977).

\section{Discussion}

Previous experiments have demonstrated that lesions of the hippocampal formation interfere with the acquisition of conditioned fear reactions to contextual cues (Selden et al. 1991; Phillips and LeDoux 1992) or the expression of fear reactions previously conditioned to contextual cues (Kim and Fanselow 1992). In these studies contextual cues were static stimuli present in a chamber where a phasic CS was paired with a US. In this study we found that in the absence of a phasic CS paired with the US, hippocampal lesions did not disrupt the conditioning of fear reactions to static contextual stimuli. We refer to training procedures in which there is a phasic CS that is explicitly paired with a US as background contextual fear conditioning and training procedures where an explicitly paired phasic CS is absent as foreground contextual fear condition. This distinction is not usually made in either experimental or theoretical work on context, but it has important implications.

Lesions of the dorsal hippocampus did not prevent the acquisition of freezing to nonphasic cues in either foreground procedure. This was true despite the fact that lesions judged by the same criteria interfered with freezing in the background procedure. Nevertheless, the two foreground procedures should not be viewed as functionally equivalent. The rate of acquisition of conditioned freezing responses to static cues was faster in the Unpaired than in the US Alone control group. This suggests that animals in the Unpaired and US Alone procedures condition to (or attend to) different aspects of the environment. Also, hippocampal lesioned animals in the Unpaired group had a slower rate of acquisition than the controls in this group. The presence of the explicitly unpaired CS, which appears to develop inhibitory properties in this procedure (see Rescorla and Wagner 1972; Cunningham et al. 1977; Results, this paper), may facilitate conditioning to the context, at least in control subjects. Hippocampal le-

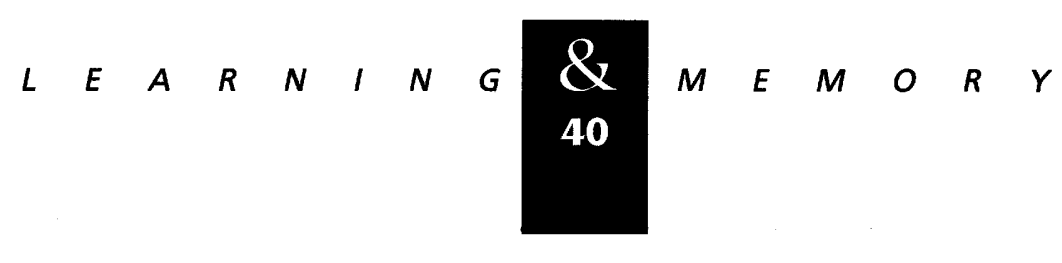


sions do not prevent contextual conditioning in this procedure, but they do interfere with this facilitation of the rate of learning by the presence of the Unpaired CS. This is an interesting effect that needs to be studied further to be understood.

Our findings are generally consistent with results obtained by Good and Honey (1991) in a study of appetitive conditioning. They found that hippocampal lesioned rats were impaired at learning that a CS was reinforced with food in one environment but not in another, but they were not impaired at learning that one context was associated with food but another was not. Though not described in this way by Good and Honey, these are essentially background (explicit CS present) and foreground (no explicit CS present) appetitive conditioning procedures and only the former was found to be sensitive to hippocampal damage.

When a salient, explicit, phasic CS that reliably predicts the occurrence of a US is present, conditioned responses are more likely to develop to it than to other stimuli in the environment (e.g., Kamin 1968, 1969; Rescorla and Wagner 1972; Odling-Smee 1975, 1978; Mackintosh 1983). Although the salient and predictive CS "overshadows" the other stimuli, some conditioning can occur to the static, background stimuli (Rescorla and Wagner 1972; Gordon et al. 1981; Marlin 1981, 1982; Kim and Fanselow 1992; Phillips and LeDoux 1992). However, when a US occurs in the absence of an explicit, predictive CS, any conditioning that results as a consequence of US occurrence must involve static stimuli. Because static stimuli are always present, they are all equally predictive (or nonpredictive) of the US. As a result, the strongest associations will probably be formed with the most salient static stimuli, which, though continuously present, become foreground conditioned stimuli. Conditioning to less salient static stimuli may still occur, but the associations formed should be in the background and weaker.

We believe that hippocampal damage interfered with background fear conditioning in all three training procedures in this study. Thus, in the Paired group, hippocampal lesions interfered with conditioning to stimuli that occurred in the background against the phasic CS foreground stimulus. In the US Alone and Unpaired groups, hippocampal lesions probably also interfered with conditioning to static stimuli that were in the background, but in this case, the foreground was also accounted for by static stimuli. Because both the background and foreground stimuli are static and always present, conditioned responses controlled by background and foreground events cannot be distinguished. A deficit in background contextual conditioning would therefore be undetectable as it would be masked by conditioning that occurs to the static foreground.

Why do animals with hippocampal lesions given paired training not condition to static cues? This is evident from a lack of freezing during times when there is no CS present. In the absence of a functional hippocampal system, the subjects may be reduced to forming single cue associations. As is widely accepted, the association between a single, phasic CS and a US in fear conditioning is mediated to a large degree (though probably not exclusively) by processes occurring in the amygdala (Davis 1992; Kapp et al. 1992; LeDoux 1992). Damage to the hippocampus leaves this process intact (Rickert et al. 1978; Selden et al. 1991; Phillips and LeDoux 1992). In contrast, theories of hippocampal function variably focus on its role in processing spatial relations (O'Keefe and Nadel 1978; McNaughton and Barnes 1990; Rolls 1991), configural associations (Sutherland and Rudy 1989), relational representations (Eichenbaum et al. 1988, 1992), or declarative (as opposed to nondeclarative) meomory (Eichenbaum 1991; Squire 1992). These theories emphasize a role for the hippocampus in forming associations between multiple cues and/or the creation of polymodal representations and suggest that single cues may be processed independently of hippocampal involvement. To the extent that background stimuli occur against some foreground event, our interpretation of the present findings in terms of an effect of hippocampal lesions on the processing of background stimuli is consistent with this general view of multiple cue associations. To the extent that foreground stimuli (phasic or static) enter into associations with the US as single cues, their conditioning is mediated by the amygdala and these associations would survive hippocampal damage.

We cannot rule out a role for the hippocampus in contextual conditioning in the foreground conditioning procedures (Unpaired and US Alone training). However, whatever role the hippocampus may perform in foreground contextual conditioning, it is likely to be different from its role in background contextual conditioning, given that similar lesions of hippocampus have different effects on background and foreground contextual conditioning. At the same time, it is also possible

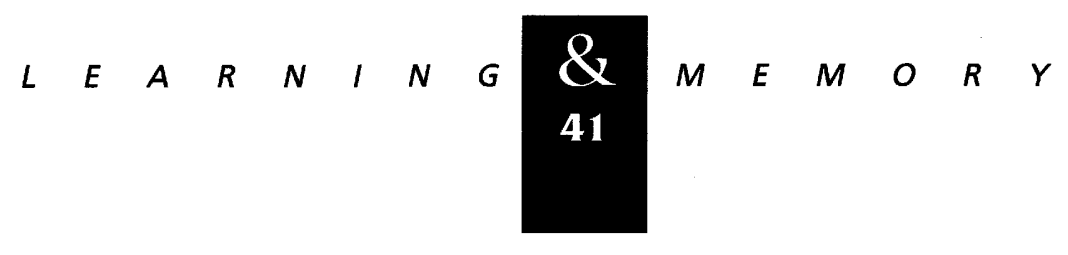


that under different training conditions, hippocampal lesions might interfere with conditioning in an Unpaired or US Alone procedure. This has been observed by Blanchard and Fial (1968) and by Kim and Fanselow (1994).

An alternative explanation of our results is that the lesion effects are more related to the strength of conditioning that results from different training procedures rather than to the type of stimuli involved (background vs. foreground). That is, in the Paired procedure, the more salient CS overshadows the context, and as a result, conditioning to the context is weaker. Hippocampal damage might be more disruptive to weak associations. However, whereas the strength of conditioning to contextual stimuli (judged by rate of acquisition) is essentially the same in the Paired and US Alone group, hippocampal damage only prevented acquisition of contextual conditioning in the Paired group. It might also be argued that our results are attributable to an effect of hippocampal lesions on overshadowing, an effect that has been reported in some studies (Rickert et al. 1979; Schmajuk et al. 1983). In contrast to controls, lesioned animals in these studies express conditioned responses to both salient and less salient stimuli, suggesting that the hippocampus is involved in detecting salience. However, the effects that we observed are opposite to these. Hippocampal damage prevented conditioning to the less salient background stimuli in the Paired group rather than increased responses to the background events. It is unlikely that our results are attributable to a disruption of overshadowing.

The relegation of the hippocampus to a role in forming associations to background events in contextual ear conditioning does not reduce the importance of this aspect of learning. Background events are crucial in setting the scene, or context, in which the CS is to be interpreted. A CS presented out of the conditioning context is often less effective than one presented within it (Balaz et al. 1982; Hall and Honey 1989; Penick and Solomon 1991). Our distinction between the CS and the context, on one hand, and foreground and background events, on the other, simply demarcates various processes that are relevant to the overall learning situation.

\section{Acknowledgments}

This work was supported by National Science Foundation IBN9209646 and U.S. Public Health Service grants R37MH38774 and K02MH00956.
The publication costs of this article were defrayed in part by payment of page charges. This article must therefore be hereby marked "advertisement" in accordance with 18 USC section 1734 solely to indicate this fact.

\section{References}

Balaz, M.A., S. Capra, W.J. Kasprow, and R.R. Miller. 1982. Latent inhibition of the conditioning context: Further evidence of contextual potentiation of retrieval in the absence of appreciable context-US associations. Anim. Learn. Behav. 10: 242-248.

Blanchard, R.J. and D.C. Blanchard. 1969a. Crouching as an index of fear. J. Comp. Physiol. Psychol. 67: 370-375.

1969b. Passive and active reactions to fear-eliciting stimuli. J. Comp. Physiol. Psychol. 68:(1) 129-135.

1972. Innate and conditioned reactions to threat in rats with amygdaloid lesions. I. Comp. Physiol. Psychol. 81:(2) 281-290.

Blanchard, R.J. and R.A. Fial. 1968. Effects of limbic lesions on passive avoidance and reactivity to shock. J. Comp. Physiol. Psychol. 66: 606-612.

Bolles, R.C. and M.S. Fanselow. 1980. A perceptual-defensive-recuperative model of fear and pain. Behav. Brain Sci. 3: 291-323.

Bouton, M.E. and R.C. Bolles. 1980. Conditioned fear assessed by freezing and by the suppression of three different baselines. Anim. Learn. Behav. 8: 429-434.

Bouton, M.E. and D.A. King. 1983. The contextual control of extinction of conditioned fear: Test for the associative value of the context. J. Exp. Psychol. Anim. Behav. Processes 9: 248-265.

Brown, J.S., H.I. Kalish, and I.E. Farber. 1951. Conditioned fear as revealed by magnitude of startle response to an auditory stimulus. J. Exp. Psychol. 41: 317-328.

Bueno, O.F.A., M.G.M. Oliveira, A.C. Pomarico, and E.B. Gugliano. 1993. A dissociation between the proactive ECS effects on inhibitory avoidance learning and on classical fear conditioning. Behav. Neural Biol. 59:(3) 180-185.

Cunningham, C.L., R.D. Fitzgerald, and D.L. Francisco. 1977. Excitatory and inhibitory consequences of explicitly unpaired and truly random conditioning procedures on heart rate in rats. Anim. Learn. Behav. 5:(2) 135-142.

Davis, M. 1992. The role of the amygdala in conditioned fear. In The amygdala: Neurobiological aspects of emotion, memory, and mental dysfunction (ed. J.P. Aggleton), pp. 255-306. Wiley-Liss, New York.

Eichenbaum, H. 1991. The hippocampal system and declarative memory in animals. J. Cognitive Neurosci. 4: 217-231.

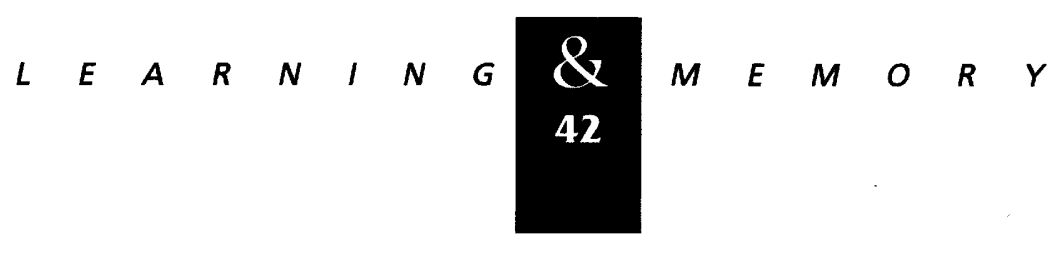


Eichenbaum, H., A. Fagan, P. Mathews, and N. Cohen. 1988. Hippocampal system discrimination learning in rats: Impairment or facilitation depending on representational demands. Behav. Neurosci. 102: 331-339.

Eichenbaum, H., T. Otto, and N.J. Cohen. 1992. The hippocampus-What does it do? Behav. Neural Biol. 57: 2-36.

Estes, W.K. and B.F. Skinner. 1941. Some quantitative properties of anxiety. J. Exp. Psychol. 29: 390-400.

Fanselow, M.S. 1980. Conditional and unconditional components of postshock freezing. Pavlovian J. Biol. Sci. 15: $177-182$.

1990. Factors governing one-trial contextual conditioning. Anim. Learn. Behav. 18: 264-270.

Gibbon, J. and P. Balsam. 1981. Spreading associations in time. In Autoshaping and conditioning theory (ed. C.M. Locurto, H.S. Terrace, and J. Gibbon), pp. 219-253. Academic Press, New York.

Good, M. and R.C. Honey. 1991. Conditioning and contextual retrieval in hippocampal rats. Behav. Neurosci. 105:(4) 499-509.

Gordon, W.C., K.M. McCracken, N. Dess-Beech, and R.R. Mowrer. 1981. Mechanisms for the cueing phenomenon: The addition of the cueing context to the training memory. Learn. Motiv. 12: 196-211.

Hall, G. and R.C. Honey. 1989. Contextual effects in conditioning, latent inhibition, and habituation: Associative and retrieval functions of contextual cures. J. Exp. Psychol. Anim. Behav. Processes 15: 232-241.

Hirsh, R. 1974. The hippocampus and contextual retrieval of information from memory: A theory. Behav. Biol.

12: $421-444$.

Hunt, H.F. and J.V. Brady. 1955. Some effects of punishment and intercurrent "anxiety" on a simple operant J. Comp. Physiol. Psychol. 48: 305-310.

Kamin, L.J. 1968. "Attention-like" processes in classical conditioning. In Miami symposium on the prediction of behavior: Aversive stimulation (ed. M.R. Jones), pp. 9-33. University of Miami Press, Miami, FL.

1969. Predictability, surprise, attention, and conditioning. In Punishment and aversive behavior (ed. R. Church and B. Campbell), pp. 276-296.

Appleton-Century-Crofts, New York.

Kamin, L.J., C.J. Brimer, and A.H. Black. 1963. Conditioned suppression as a monitor of fear of the CS in the course of avoidance training. J. Comp. Physiol. Psychol. 56: 497-501.

Kapp, B.S., P.J. Whalen, W.F. Supple, and J.P. Pascoe. 1992. Amygdaloid contributions to conditioned fear. In The amygdala: Neurobiological aspects of emotion, memory, and mental dysfunction (ed. J.P. Aggleton), pp. 229-254.

Wiley-Liss, New York.

Kim, J.J. and M.S. Fanselow. 1992. Modality-specific retrograde amnesia of fear. Science 256: 675-677.

Kim, J.J., R.A. Rison, and M.S. Fanselow. 1994. Effects of amygdala, hippocampus, and periaqueductal gray lesions on short- and long-term contextual fear. Behav. Neurosci.

107: 1093-1098.

LeDoux, J.E. 1990. Information flow from sensation to emotion: Plasticity in the neural computation of stimulus value. In Learning and computational neuroscience (ed. $\mathrm{M}$. Gabriel and J. Moore), pp. 3-51. Bradford Books/MLT Press, Cambridge, MA.

1992. Brain mechanisms of emotion and emotional learning. Curr. Opin. Neurobiol. 2: 191-198.

LeDoux, J.E., A. Sakaguchi, and D.J. Reis. 1984. Subcortical efferent projections of the medial geniculate nucleus mediate emotional responses conditioned to acoustic stimuli. J. Neurosci. 4: 683-698.

LeDoux, J.E., P. Cicchetti, A. Xagoraris, and L.M. Romanski. 1990. The lateral amygdaloid nucleus: Sensory interface of the amygdala in fear conditioning. J. Neurosci.

10: 1062-1069.

Mackintosh, N.J. 1983. Conditioning and associative learning (ed. D.E. Broadbent, J.L. McGaugh, N.J. Mackintosh, M.I. Posner, E. Tulving, and L. Weiskrantz). Oxford University Press, Oxford, UK.

Marlin, N.A. 1981. Contextual associations in trace conditioning. Anim. Learn. Behav. 9: 519-523.

1982. Within-compound associations between the context and the conditioned stimulus. Learn. Motiv. 13: $526-541$.

McAllister, W.R. and D.E. McAllister. 1971. Behavioral measurement of conditioned fear. In Aversive conditioning and learning (ed. F.R. Brush), pp. 105-179. Academic Press, New York.

McNaughton, B.L. and C.H. Barnes. 1990. From cooperative synaptic enhancement to associative memory: Bridging the abyss. Sem. Neurosci. 2: 403-406.

Miller, R.R. and L.D. Matzel. 1988. The comparator hypothesis: A response rule for the expression of associations. In The psychology of learning and motivation (ed. G.H. Bower), pp. 51-92. Academic Press, New York.

Nadel, L. and J. Willner. 1980. Context and conditioning: A place for space. Physiol. Psychol. 8:(2) 218-228.

O'Keefe, J. and L. Nadel. 1978. The hippocampus as a cognitive map. Clarendon Press, Oxford, UK.

Odling-Smee, F.J. 1975. The role of background stimuli

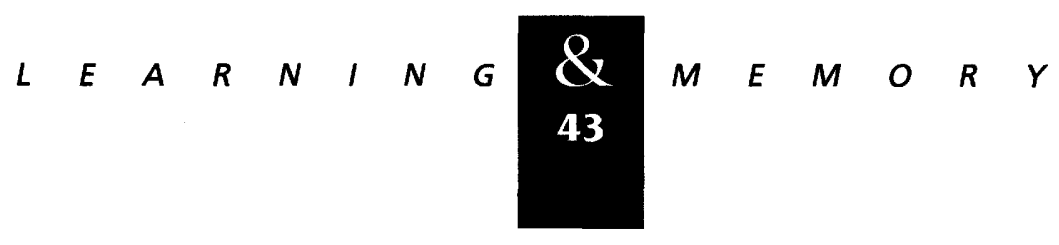


Phillips and Leboux from learnmem.cshlp.org on April 26, 2023 - Published by Cold Spring Harbor Laboratory Press

during Pavlovian conditioning. Q. J. Exp. Psychol. 27: $161-169$.

1978. The overshadowing of background stimuli by an informative CS in aversive Pavlovian conditioning with rats. Anim. Learn. Behav. 6: 43-51.

Paxinos, G. and C. Watson. 1986. The rat brain in stereotaxic coordinates. Academic Press, Sydney, Australia.

Penick, S. and P.R. Solomon. 1991. Hippocampus, context, and conditioning. Behav. Neurosci. 105: 611-617.

Phillips. R.G. and J.E. LeDoux. 1992. Differential contribution of amygdala and hippocampus to cued and contextual fear conditioning. Behav. Neurosci.

106: 274-285.

Rescorla, R.A. and A.R. Wagner. 1972. A theory of Pavlovian conditioning: Variations in the effectiveness of reinforcement and nonreinforcement. In Classical conditioning II: Current research and theory (ed. A.H. Black and W.F. Prokasy), pp. 64-99. Appleton-Century-Crofts, New York.

Rickert, E.J., T.L. Bennett, P.L. Lane, and J. French. 1978. Hippocampectomy and the attenuation of blocking. Behav. Biol. 22: 147-160.

Rickert, E.J., J.F. Lorden, R. Dawson Jr., E. Smyly, and M.F. Callahan. 1979. Stimulus processing and stimulus selection in rats with hippocampal lesions. Behav. Neural Biol.

27: 454-465.

Rolls, E.T. 1991. Functions of the primate hippocampus in spatial and nonspatial memory. Hippocampus 1: 258-261.

Schmajuk, N.A., N.E. Spear, and R.L. Isaacson. 1983.

Absence of overshadowing in rats with hippocampal lesions. Physiol. Psychol. 11: 59-62.

Selden, N.R.W., B.J. Everitt, L.E. Jarrard, and T.W. Robbins. 1991. Complementary roles for the amygdala and hippocampus in aversive conditioning to explicit and contextual cues. Neuroscience 42: 335-350.

Squire, L.R. 1992. Memory and the hippocampus: A synthesis from findings with rats, monkeys, and humans. Psychol. Rev. 99:(2) 195-231.

Sutherland, R.J. and R.J. McDonald. 1990. Hippocampus, amygdala and memory deficits in rats. Behav. Brain Res. 37: 57-79.

Sutherland, R.J. and J.W. Rudy. 1989. Configural association theory: The role of the hippocampal formation in learning, memory, and amnesia. Psychobiology 17: 129-144.

Winocur, G. and J. Olds. 1978. Effects of context manipulation on memory and reversal learning in rats with hippocampal lesions. J. Comp. Physiol. Psychol.

92:(2) 312-321.
Winocur, G., J.N.P. Rawlins, and J.A. Gray. 1987. The hippocampus and conditioning to contextual cues. Behav. Neurosci. 101: 617-625.

Received July 29, 1993; accepted in revised form December 20, 1993. 


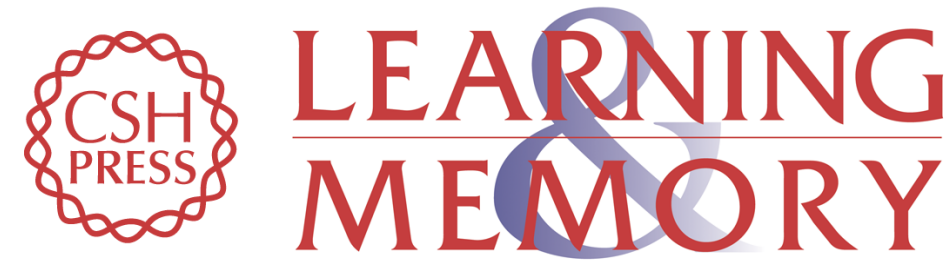

\section{Lesions of the dorsal hippocampal formation interfere with background but not foreground contextual fear conditioning.}

R G Phillips and J E LeDoux

Learn. Mem. 1994, 1:

Access the most recent version at doi:10.1101//m.1.1.34

References

License

Email Alerting Service
This article cites 46 articles, 3 of which can be accessed free at: http://learnmem.cshlp.org/content/1/1/34.full.html\#ref-list-1

Receive free email alerts when new articles cite this article - sign up in the box at the top right corner of the article or click here. 